\title{
Perspectives on Brown Adipose Tissue Imaging: Insights from Preclinical and Clinical Observations from the Last and Current Century
}

\author{
John P. Crandall and Richard L. Wahl \\ Mallinckrodt Institute of Radiology, Washington University School of Medicine, St. Louis, Missouri
}

Brown adipose tissue (BAT) was first described in the 16th century, but until late last century had mainly been considered a tissue with the function of nonshivering thermogenesis, maintaining body temperature in key organs in newborns who have high body surface areas relative to their weight and thus marked radiative heat loss. BAT was believed to have substantially disappeared by adulthood. Molecular imaging with ${ }^{18} \mathrm{~F}$-FDG PET and PET combined with CT, as well as imaging with ${ }^{131}$ I-metaiodobenzylguanidine (MIBG) beginning late last century have shown BAT to be present and active well into adulthood. This review highlights key aspects of BAT biology, early empiric observations misidentifying BAT, pitfalls in image interpretation, and methods to intentionally reduce BAT uptake, and outlines multiple imaging methods used to identify BAT in vivo. The therapeutic potential of increasing the amount or activity of BAT for weight loss and improvement of glucose and lipid profiles is highlighted as a major opportunity. Molecular imaging can help dissect the physiology of this complex dynamic tissue and offers the potential for addressing challenges separating "active BAT" from "total BAT." Research in BAT has grown extensively, and ${ }^{18} \mathrm{~F}$-FDG PET is the key imaging procedure against which all other BAT imaging methods must be compared. Given the multiple functions of BAT, it is reasonable to consider it a previously unrecognized endocrine tissue and thus an appropriate topic for review in this supplement to The Journal of Nuclear Medicine.

Key Words: ${ }^{18} \mathrm{~F}$-fluorodeoxyglucose (FDG); brown adipose tissue (BAT); computed tomography (CT); metaiodobenzylguanidine (MIBG); positron emission tomography (PET)

J Nucl Med 2021; 62:34S-43S

DOI: 10.2967/jnumed.120.246991

\section{B} rown adipose tissue (BAT or brown fat) was first described by Swiss physician and naturalist Conrad Gessner in the 16th century (1). Originally termed the "hibernating gland," BAT was assigned various physiologic roles over the following centuries, including postulating it to be part of the thymus, as an alternate food reservoir, and as an endocrine gland during several different periods (2). Eventually, BAT was identified as a thermogenic organ and the primary facilitator of nonshivering thermogenesis in

\footnotetext{
Received Sep. 28, 2020; revision accepted Dec. 22, 2020.

For correspondence or reprints, contact Richard L. Wahl (rwahl@wustl. edu).

COPYRIGHT (C) 2021 by the Society of Nuclear Medicine and Molecular Imaging.
}

mammals (3), although its function as an endocrine organ is increasingly recognized (4).

Despite early histologic evidence to the contrary, it was generally assumed any BAT possessed by adult humans was mostly dormant $(3,5)$. The realization that active BAT was present in adult humans came unexpectedly from problems arising with new clinical imaging techniques. The senior author of this paper vividly recalls examining scans of children and young adults using the then "new" compound ${ }^{131}$ I-metaiodobenzylguanidine ( $\left.{ }^{131} \mathrm{I}-\mathrm{MIBG}\right)$. Uptake of ${ }^{131} \mathrm{I}$-MIBG was apparent in the supraclavicular areas of some patients and local lore from the pioneers in ${ }^{131} \mathrm{I}-\mathrm{MIBG}$ clinical use, including the late James Sisson, was that this uptake was in the "stellate ganglion," a target of interest at that time (6). This seemed an impossibly large ganglion to me and quite unusual. Descriptions of ${ }^{131}$ I-MIBG distribution at the time described instances of normal uptake in the "upper lungs" (7). In retrospect, some of these observations were likely visualization of BAT.

In the late 1980 s and early $1990 \mathrm{~s}$, the application of ${ }^{18} \mathrm{~F}-\mathrm{FDG}$ PET for the detection of tumors increased in use. Not infrequently, ${ }^{18}$ F-FDG PET image interpretations were hindered by the appearance of symmetric areas of increased uptake, most apparent in the supraclavicular area $(8,9)$. At first, this activity was mostly attributed to skeletal muscle uptake. Some of our (RL Wahl and MS Wicha, unpublished data, 1991) early studies of breast cancer treatment response with PET showed areas of ${ }^{18} \mathrm{~F}$-FDG uptake in the upper thorax and lower neck, which was absent, then present, then absent on closely spaced ${ }^{18}$ F-FDG PET studies. I (the senior author) recall a case in which I had to convince an oncologist not to treat this new ${ }^{18} \mathrm{~F}$-FDG uptake as it had appeared too quickly to represent tumor progression and then was gone on a subsequent study. Barrington et al. described this uptake and found it could be minimized by administering diazepam before ${ }^{18} \mathrm{~F}$-FDG PET imaging (8). Dr. Barrington and I, 2 early adopters of ${ }^{18}$ F-FDG PET in oncology, published in our jointly authored textbook that this uptake in the neck muscles was artifactual and caused by muscle contraction during ${ }^{18} \mathrm{~F}$-FDG uptake, due to "tense" muscles in tense patients (10). Hany et al. in 2002, Cohade et al. in 2003, and others with early access to PET combined with CT (PET/CT) posited that this supraclavicular ${ }^{18} \mathrm{~F}-\mathrm{FDG}$ activity represented uptake within activated BAT $(11-14)$. By combining ${ }^{18}$ F-FDG PET with $\mathrm{CT}$, it became clear that the ${ }^{18} \mathrm{~F}-\mathrm{FDG}$ activity in the "tense muscles" was not localizing to muscle but very clearly was in adipose tissue as it was found in anatomic areas with distinctively low Hounsfield units (HUs) only seen in fat.

Despite these informative early observations, further evidence was needed to verify that these areas of increased ${ }^{18}$ F-FDG uptake were actually in BAT. It was shown in rats and humans that ${ }^{18} \mathrm{~F}$ - 


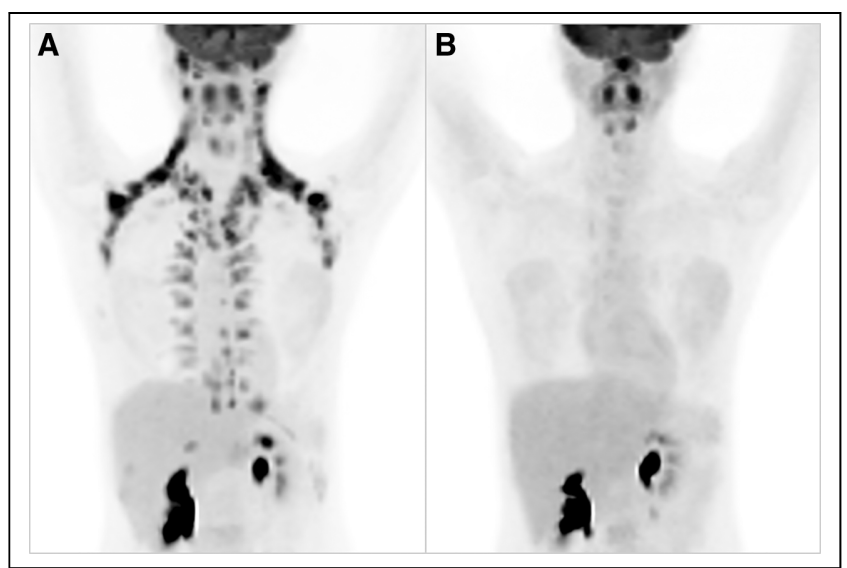

FIGURE 1. BAT can be activated by cold (coronal maximum-intensity projection [MIP], A) and inhibited using exposure to warmth and substances that block $\beta$-adrenergic receptors (coronal MIP, B), such as propranolol (this subject received $2 \mathrm{mg}$ of propranolol before ${ }^{18} \mathrm{~F}-\mathrm{FDG}$ administration).

FDG uptake could be reduced or eliminated pharmacologically (Fig. 1) using $\beta$-blockers (15). In mice, once interscapular BAT was removed, corresponding areas of previous ${ }^{18} \mathrm{~F}-\mathrm{FDG}$ uptake disappeared on subsequent PET imaging (16). In case studies of patients undergoing ${ }^{18} \mathrm{~F}$-FDG PET/CT or ${ }^{123} \mathrm{I}-\mathrm{MIBG}$ scintigraphy imaging for suspected pheochromocytomas (Fig. 2), tumors associated with increased adrenal activity and BAT recruitment, primary tumor removal resulted in resolution of previously seen bilateral supraclavicular radiotracer uptake (17).

Several PET and SPECT tracers were evaluated in rodents for their capabilities in localizing to BAT (Table 1). ${ }^{18} \mathrm{~F}-\mathrm{FDG},{ }^{131} \mathrm{I}-$ MIBG, and ${ }^{99 m}$ Tc-methoxyisobutylisonitrile ( $\left.{ }^{99 m} \mathrm{Tc}-\mathrm{MIBI}\right)$ were shown to be particularly promising agents (18-20). Knowing BAT had a high density of mitochondria, which would be expected to be targeted by ${ }^{99 \mathrm{~m}} \mathrm{Tc}-\mathrm{MIBI}$, a review of ${ }^{99 \mathrm{~m}} \mathrm{Tc}-\mathrm{MIBI}$ SPECT scans performed for suspected parathyroid adenomas (Fig. 3) revealed incidental BAT uptake of ${ }^{99 \mathrm{~m}} \mathrm{Tc}-\mathrm{MIBI}$ in $6.3 \%$ of cases $(21)$. Reviewing ${ }^{18} \mathrm{~F}$-FDG and ${ }^{18} \mathrm{~F}$-fluorodopamine (DOPA) PET/CT images, as well as ${ }^{123}$ I-MIBG SPECT images, from 96 patients evaluated for pheochromocytomas, Hadi et al. found $27 \%$ of patients showed uptake on at least 1 modality in areas known to

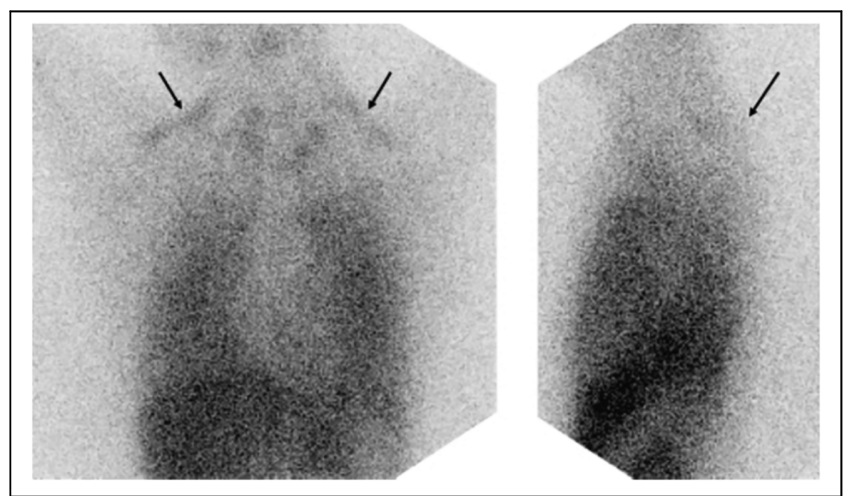

FIGURE 2. Anterior and lateral planar ${ }^{123}$ I-MIBG chest images. Positive and symmetric tracer uptake in the lower neck and shoulder region (indicated with arrows). In retrospect, these areas of uptake are likely BAT. (Reprinted with permission of (17).) contain BAT and several patients had corresponding uptake on images from multiple modalities (22).

These early observations provided a context for a series of publications in 2009 that further confirmed, using ${ }^{18} \mathrm{~F}-\mathrm{FDG} \mathrm{PET} / \mathrm{CT}$, the presence of BAT in adult humans (23-26). Cypess et al. identified active brown fat in $5.4 \%$ of 1,972 patients who underwent ${ }^{18}$ F-FDG PET/CT for various diagnostic purposes (24). Tissue samples from a subset of these patients confirmed the presence of multilocular, uncoupling protein 1 (UCP1)-immunopositive adipocytes. Virtanen et al. exposed 5 healthy subjects to a cold challenge and noted enhanced ${ }^{18} \mathrm{~F}$-FDG uptake in the supraclavicular area of all 5 subjects. Three of these subjects underwent biopsies, which showed that expression of UCP1 in the areas of increased uptake was more than 1,000 times the levels detected in white adipose tissue (WAT) (26). Another study involving healthy volunteers (10 who were lean and 14 who were obese) observed active BAT in $96 \%$ of subjects and found significantly higher BAT ${ }^{18} \mathrm{~F}$ FDG uptake in the lean subjects (25).

Observational studies have indicated active BAT is associated with a younger age, is more prevalent in females, and occurs more often in patients with lower body mass indices (BMI; Table 2). Presence of active BAT on ${ }^{18} \mathrm{~F}-\mathrm{FDG}$ PET/CT images has also been linked, in some studies, to lower fasting glucose levels and colder outdoor temperatures $(12,27)$. Data from rodent studies support a decrease in BAT mass and function with increasing age (28). In humans, Yoneshiro et al. described a BAT prevalence rate of $53 \%$ in subjects $20-30 \mathrm{y}$ of age and $7 \%$ in subjects $50 \mathrm{y}$ of age or older (29). A large prospective study, involving cold exposure to activate BAT, confirmed that subjects with ${ }^{18} \mathrm{~F}-\mathrm{FDG}$ PET/ CT-detectable BAT were more likely to be younger and to have lower adiposity-related parameters including BMI, body fat mass, and abdominal visceral and subcutaneous fat (30).

On the basis of retrospective analyses of thousands of ${ }^{18} \mathrm{~F}-\mathrm{FDG}$ PET/CT images (Table 2), it appeared the prevalence of active BAT in adults was between $3 \%$ and $9 \%$ (excluding pheochromocytoma patients). However, these were all incidental cases of BAT activation discovered under nonstandardized conditions and primarily in patients with known or suspected cancer. When prospective study designs involving cold exposure interventions were used, active BAT prevalence rates increased substantially (29). The detection and assessment of active BAT in vivo using ${ }^{18} \mathrm{~F}$ FDG PET depends on several factors including preimaging subject preparation, BAT activation technique, scanning protocols, and thresholds used to define BAT. Variations in these factors makes comparisons among studies difficult. The brown adipose reporting criteria in imaging studies (BARCIST) 1.0 is a set of guidelines proposed by a multidisciplinary group of experts intended to standardize BAT research methods and reporting to facilitate comparisons among studies (31). An important concern highlighted by the BARCIST guidelines is the type of intervention used to activate BAT. Early human BAT studies used cold challenges mainly involving exposure to ice or cold air or water $(23,25)$. The ice and water exposure paradigms are not recommended since they may also stimulate sympathetic pain responses, which could confound the effects of cooling on BAT. Most current studies use either a fixed-temperature method or an individualized approach. A fixedtemperature method involves choosing a cooling temperature and duration that is consistently used for all participants. To maximize nonshivering thermogenesis, an individualized approach involves cooling subjects (usually with a temperature-controlled vest or whole-body suit) to just above the shivering threshold. This 
TABLE 1

Animal Studies of Imaging Methods Used to Identify and Quantify BAT Activity

\begin{tabular}{|c|c|c|c|}
\hline Biologic target & Signal source & Modality & Reference \\
\hline \multirow[t]{2}{*}{ Glucose metabolism } & ${ }^{18}$ F-FDG & PET & 19 \\
\hline & ${ }^{18} \mathrm{~F}-\mathrm{FDG}$ & PET & 20 \\
\hline Adrenergic innervation & ${ }^{123} \mathrm{I}-\mathrm{MIBG}$ & SPECT & 19 \\
\hline Sympathetic innervation & ${ }^{11} \mathrm{C}-\mathrm{MRB}$ & PET & 74 \\
\hline \multirow[t]{2}{*}{ Proton gradient } & ${ }^{3} \mathrm{H}-\mathrm{TPP}$ & PET & 75 \\
\hline & ${ }^{18} \mathrm{~F}-\mathrm{FBnTP}$ & PET & 65 \\
\hline BAT-specific endothelium & Peptide fluorescence & NIR & 76 \\
\hline \multirow[t]{2}{*}{ Temperature } & Infrared radiation & IRT & 77 \\
\hline & Hyperpolarized ${ }^{129} \mathrm{Xe}$ & MR & 78 \\
\hline BAT presence & ${ }^{18} \mathrm{~F}$-FDG luminescence & Cerenkov optical imaging & 79 \\
\hline Pyruvate conversion & ${ }^{13} \mathrm{C}$-pyruvate & MR & 80 \\
\hline \multirow[t]{2}{*}{ NEFA metabolism } & Optical (AlexaFFA) & NIR & 81 \\
\hline & ${ }^{123} \mathrm{I}^{125} \mathrm{I}-\mathrm{BMIPP}$ & SPECT & 33 \\
\hline Fat distribution & $\mathrm{H}^{+}$ & MRS & 82 \\
\hline \multirow[t]{5}{*}{ Perfusion } & IR-786 & NIR & 83 \\
\hline & ${ }^{99 m} \mathrm{Tc}-\mathrm{MIBI}$ & SPECT & 18 \\
\hline & BOLD & MR & 84 \\
\hline & Oxygenation demand & fMR & 71 \\
\hline & Hyperpolarized ${ }^{129} \mathrm{Xe}$ & MR & 48 \\
\hline PD1/PDL1 expression & ${ }^{64} \mathrm{Cu}-\mathrm{NOTA}$ & PET & 86 \\
\hline \multirow[t]{2}{*}{ TSPO density } & ${ }^{18}$ F-FEPPA- $d_{2}$ & PET & 87 \\
\hline & ${ }^{64} \mathrm{CuCl}_{2} /$ disulfiram & PET & 88 \\
\hline Mitochondrial density & ${ }^{18} \mathrm{~F}-\mathrm{BODIPY}$ & PET & 89 \\
\hline WAT browning & CRANAD-29 & NIR & 90 \\
\hline
\end{tabular}

$\mathrm{NIR}=$ near infrared; IRT = infrared thermography; MRS = magnetic resonance spectroscopy; fMR = functional MR; PD1 = programmed death-1; PDL1 = programmed death-ligand 1.

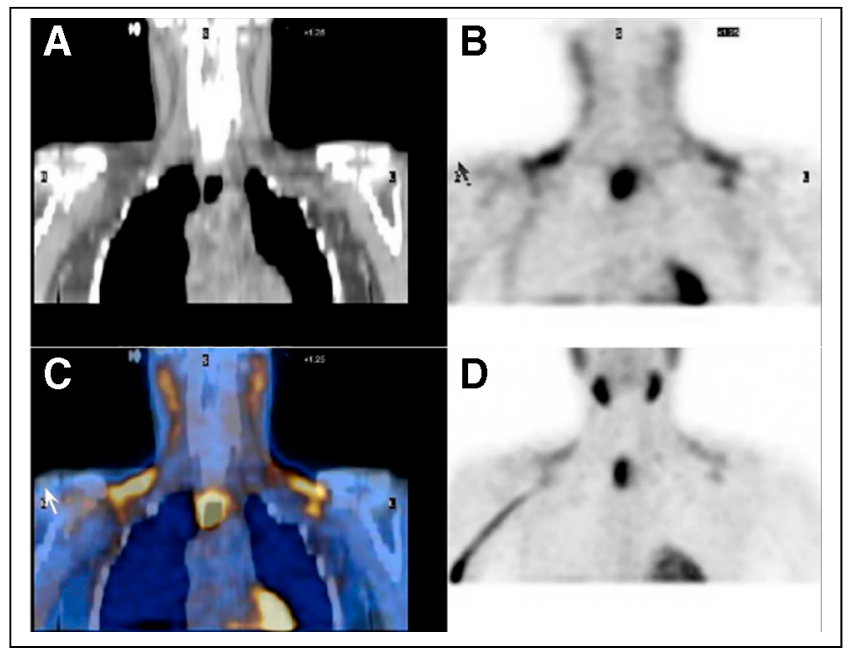

FIGURE 3. SPECT imaging performed on a 26 -y-old woman with primary hyperparathyroidism shows supraclavicular BAT in addition to right superior mediastinal parathyroid adenoma (confirmed at time of surgery). ${ }^{99 m}$ TC-MIBI uptake seen on SPECT clearly fuses to BAT. Selected coronal (A-D) images of CT (A), SPECT (B), fused SPECT/CT (C), and maximumintensity projection (D). (Reprinted from (21).) method is recommended for studies with heterogeneous populations and for studies assessing interventions intended to alter BAT activity or volume.

\section{BAT BIOLOGY}

BAT is unique both structurally and functionally. Compared with the larger, round adipocytes contained in WAT, brown adipocytes are smaller and polygonal in shape. BAT contains large amounts of mitochondria (in part, the source of its brown color) containing UCP1 (Supplemental Fig. 1; supplemental materials are available at http://jnm.snmjournals.org), a protein responsible for separating the mitochondrial proton gradient from ATP synthesis, resulting in thermogenesis. BAT depots are densely sympathetically innervated and highly vascularized, which facilitates the dissipation of heat and the exchange of glucose, oxygen, and nonesterified fatty acids (NEFA) (32).

Much of our understanding of BAT biology comes from the use of rodent models. In rodents, the interscapular region contains the primary BAT depot, and additional BAT depots are found in paravertebral, supraclavicular, infrascapular, inguinal, and perirenal areas. In humans, the most active BAT depots tend to be located in the supraclavicular and paravertebral regions with additional 
TABLE 2

Observations from Retrospective Analyses of Clinically Obtained Images Showing Associations Between Incidental BAT Activation and Age, Sex, BMI, Fasting Glucose Levels, and Outdoor Temperature

\begin{tabular}{|c|c|c|c|c|c|c|c|c|c|}
\hline \multirow[b]{2}{*}{ Reference } & \multirow[b]{2}{*}{$n$} & \multirow[b]{2}{*}{ Prevalence } & \multirow[b]{2}{*}{ Radiotracer } & \multirow[b]{2}{*}{ Location } & \multicolumn{5}{|c|}{ Association with BATpositivity } \\
\hline & & & & & Age & Sex & $\mathrm{BMI}$ & $\begin{array}{l}\text { Fasting } \\
\text { glucose }\end{array}$ & $\begin{array}{c}\text { Outdoor } \\
\text { temperature }\end{array}$ \\
\hline 11 & 638 & 0.025 & ${ }^{18} \mathrm{~F}-\mathrm{FDG}$ & Zurich, $\mathrm{CH}$ & $\mathrm{NA}^{*}$ & $\mathrm{ND}^{\dagger}$ & $L^{\ddagger}$ & NA & NA \\
\hline 13 & 347 & 0.04 & ${ }^{18} \mathrm{~F}-\mathrm{FDG}$ & Baltimore, MD & NA & $\mathrm{F}^{\S}$ & NA & NA & NA \\
\hline 12 & 905 & 0.069 & ${ }^{18} \mathrm{~F}-\mathrm{FDG}$ & Baltimore, MD & $Y^{\|}$ & $\mathrm{F}$ & ND & NA & $C^{9}$ \\
\hline 99 & 863 & 0.037 & ${ }^{18} \mathrm{~F}-\mathrm{FDG}$ & New York, NY & $\mathrm{Y}$ & $\mathrm{F}$ & ND & NA & NA \\
\hline 100 & 1159 & 0.030 & ${ }^{18} \mathrm{~F}-\mathrm{FDG}$ & New York, NY & $\mathrm{Y}$ & $\mathrm{F}$ & NA & NA & $\mathrm{C}$ \\
\hline 21 & 205 & 0.063 & ${ }^{99 m} \mathrm{Tc}-\mathrm{MIBI}$ & Baltimore, MD & $\mathrm{Y}$ & ND & NA & NA & NA \\
\hline 24 & 1972 & 0.054 & ${ }^{18} \mathrm{~F}-\mathrm{FDG}$ & Boston, MA & $\mathrm{Y}$ & $\mathrm{F}$ & $\mathrm{L}$ & $\mathrm{L}^{\#}$ & $\mathrm{C}$ \\
\hline 49 & 3614 & 0.046 & ${ }^{18} \mathrm{~F}-\mathrm{FDG}$ & Nottingham, U.K. & Y & $\mathrm{F}$ & $\mathrm{L}$ & ND & C \\
\hline 27 & 2934 & 0.085 & ${ }^{18} \mathrm{~F}-\mathrm{FDG}$ & Sydney, AU & $\mathrm{Y}$ & $\mathrm{F}$ & $\mathrm{L}$ & $\mathrm{L}$ & ND \\
\hline 101 & 908 & 0.062 & ${ }^{18} \mathrm{~F}-\mathrm{FDG}$ & Baltimore, MD & $\mathrm{Y}$ & $\mathrm{F}$ & $\mathrm{L}$ & L & NA \\
\hline 48 & 4842 & 0.068 & ${ }^{18} \mathrm{~F}-\mathrm{FDG}$ & Sherbrooke, Quebec, CA & $\mathrm{Y}$ & $\mathrm{F}$ & L & $\mathrm{L}$ & $\mathrm{C}$ \\
\hline 102 & 386 & 0.094 & ${ }^{18} \mathrm{~F}-\mathrm{FDG}$ & Pretoria, ZA & $\mathrm{Y}$ & $\mathrm{F}$ & $\mathrm{L}$ & NA & $\mathrm{C}$ \\
\hline 103 & 6454 & 0.034 & ${ }^{18} \mathrm{~F}-\mathrm{FDG}$ & Rome, IT & $\mathrm{Y}$ & $\mathrm{F}$ & $\mathrm{L}$ & $\mathrm{L}$ & $\mathrm{C}$ \\
\hline 50 & 10432 & 0.036 & ${ }^{18} \mathrm{~F}-\mathrm{FDG}$ & Amsterdam, NL & $Y$ & $\mathrm{~F}$ & $\mathrm{~L}$ & L & $\mathrm{C}$ \\
\hline 104 & 4852 & 0.054 & ${ }^{18} \mathrm{~F}-\mathrm{FDG}$ & Tuebingen, DE & $Y$ & $\mathrm{~F}$ & $\mathrm{~L}$ & ND & ND \\
\hline $\begin{array}{l}{ }^{*} \text { Not assess } \\
{ }^{+} \text {No signific } \\
{ }^{\ddagger} \text { Individuals } \\
\text { \$Females m } \\
\text { "Younger in } \\
\text { "Y Detectable } \\
\text { "Individuals } \\
\text { BMI = body }\end{array}$ & $\begin{array}{l}\text { ed. } \\
\text { ant differe } \\
\text { with lowe } \\
\text { ore likely } \\
\text { dividuals } \\
\text { BAT ass } \\
\text { with lowe } \\
\text { mass in }\end{array}$ & $\begin{array}{l}\text { nce found. } \\
\text { BMls more } \\
\text { to exhibit det } \\
\text { more likely to } \\
\text { ciated with c } \\
\text { fasting gluc } \\
\text { lex. }\end{array}$ & $\begin{array}{l}\text { kely to exhibit } \\
\text { ctable BAT. } \\
\text { exhibit detecta } \\
\text { lder ambient o } \\
\text { se levels more }\end{array}$ & $\begin{array}{l}\text { detectable BAT. } \\
\text { ble BAT. } \\
\text { utdoor temperatures } \\
\text { likely to exhibit detectable }\end{array}$ & & & & & \\
\hline
\end{tabular}

foci commonly seen in the axillary, intercostal, mediastinal, and perirenal areas. A challenge in the field is the inability to directly compare human and rodent fat pads, as discussed previously by Zhang et al. (33). Rodents experience substantially different environmental pressures than humans due to their vastly different volume-to-surface ratios, muscle mass, and fat depot perfusion. Classic experiments by Foster and Frydman demonstrated that cold exposure in rodents increases BAT blood flow by up to 20 -fold, achieving a maximal rate of more than $1,000 \mathrm{~mL} / 100$ $\mathrm{g} / \mathrm{min}$ (34). However, this rate is about 100 times greater than what has been observed in humans, which has been shown to vary between $10.0 \pm 2.4$ and $15.9 \pm 4.9 \mathrm{~mL} / 100 \mathrm{~g} / \mathrm{min}(35,36)$. The limits associated with applying rodent data to humans have been problematic in the field. For example, rodent studies have clearly demonstrated that administration of $\beta_{3}$-adrenergic agonists causes dramatic weight loss in rodents, but this effect has not been consistently duplicated in humans (37). Although the $\beta_{3}$-receptors are clearly implicated in BAT activation in rodent studies, $\beta_{2}$-receptors appear to be more important in humans based on very recent data (38). Exercise is another area of BAT study that seems to differ between humans and rodents. Several rodent studies have shown that exercise increases the browning of WAT in rodents, but this may not be the case in humans (39). Clearly, caution should be exercised when applying rodent data to humans.
In vivo, BAT can be absent, present and inactive, and present and activated. It is unclear whether there is an additional state in which BAT is present, but not capable of being activated immediately, but potentially activatable over time (recruitable). When the sympathetic nervous system is activated as a result of cold exposure, norepinephrine is released, which binds to adrenergic receptors $\left(\beta_{1^{-}}, \beta_{2^{-}}\right.$, and $\beta_{3}$-adrenoceptors) expressed on BAT cell surfaces, causing an increase in cytosolic cyclic adenosine monophosphate levels (Supplemental Fig. 2) (40). Elevated levels of catechols are likely the explanation for BAT activation and expansion in select patients with pheochromocytomas due to chronic exposure of BAT to circulating epinephrine. Subsequently, intracellular NEFA concentrations increase as a result of triglyceride lipolysis. Most likely, liberated fatty acids then bind to and activate UCP1, resulting in the extrication of the proton gradient from ATP synthesis, and thus, heat generation (41). Although intracellular triglycerides provide much of the fuel for initial BAT activation, additional substrates are needed during periods of ongoing thermogenesis, which are provided in the form of circulating glucose or fatty acids. The increased glucose accumulation seen on ${ }^{18}$ F-FDG PET does not mean that increased glucose accumulation in BAT is the sole immediate source of energy for heat generation. Indeed, Sanchez-Delgado et al. compared levels of cold-induced thermogenesis, as assessed using indirect 
calorimetry, with ${ }^{18}$ F-FDG PET-assessed BAT volume and activity levels and found no association between cold-induced thermogenesis and BAT glucose uptake (42). Glucose taken up within thermogenic adipocytes either undergoes glycolysis and subsequent oxidation, participates in mitochondrial anaplerosis (in the form of pyruvate) and production of reducing equivalents to maintain fatty acid oxidation, or is directed toward de novo lipogenesis and fatty acid synthesis to activate UCP1 and to fuel thermogenesis. However, the precise ratios and the dynamics of these metabolic fates remains unclear and warrants further study.

Although much of the interest in BAT has been its ability to consume glucose and contribute to net caloric balance, it has additional functions that appear to be endocrinelike in nature. In animal models, BAT transplants can cure diabetes in the transplant recipients in more than $50 \%$ of cases (43). This cure does not result solely from increased glucose consumption, but appears to be due to factors released from BAT that have systemic effects on glucose metabolism. Adipokines released from BAT, termed "BATokines," are additional substances preferentially released by BAT versus WAT, which may have endocrine effects (Supplemental Fig. 3) (44). A primary example is fibroblast growth factor 21 (FGF21), which was among the first proposed endocrine signals acting as a BATokine, given the strong release of FGF21 by BAT under conditions of thermogenic activation (45). Increased FGF21 augments energy catabolism by promoting glucose uptake and oxidation via Glut1 expression and activation of lipolysis and reduction of fatty acid synthesis. Mild cold exposure has been shown to increase plasma FGF21 levels with BAT activation (46). BAT presence is further associated with increased levels of interleukin-6 (IL-6), insulinlike growth factor 1 (IGF-1), neureregulin 4 (NRG4), and 12,13-dihydroxy-9Z-octadecenoic acid (12,13-diHOME), as well as other endocrine factors. A full discussion of the myriad endocrine functions possibly associated with BAT is beyond this review, which is primarily focused on the imaging of BAT, but several recent reviews extensively describe this topic $(4,47)$. It appears that even in humans, in which the BAT mass is relatively small compared with total body mass, active BAT is associated with a healthier metabolic profile. Thus, whereas BAT can help to combat caloric imbalance by consuming glucose and lipids, its most important function may be in improving the overall systemic metabolic profile via endocrine signaling.

\section{BAT IMAGING}

The discovery of active BAT in adult humans was facilitated by observations seen on ${ }^{18} \mathrm{~F}$-FDG PET and PET/CT as discussed previously, and ${ }^{18} \mathrm{~F}$-FDG PET remains the most commonly used method for the assessment of metabolically active BAT. ${ }^{18} \mathrm{~F}-\mathrm{Sev}-$ eral additional imaging methods (Table 3 ) have been used to help quantify human BAT and explore different aspects of its function.

\section{Oxidative Metabolism}

Although it is clear from both retrospective and prospective studies that active BAT (as assessed using ${ }^{18} \mathrm{~F}-\mathrm{FDG}$ PET) is negatively correlated with obesity, understanding the extent to which this represents a contribution to overall energy expenditure requires additional information (48-51). Ouellet et al. demonstrated, using ${ }^{11} \mathrm{C}$-acetate PET, increases in cold-induced oxidative metabolism in BAT, but not substantially in muscle or WAT. Total energy expenditure was also associated with increases in BAT oxidative metabolism (52). Using triple oxygen dynamic PET scans $\left({ }^{15} \mathrm{O}-\mathrm{H}_{2} \mathrm{O},{ }^{15} \mathrm{O}-\mathrm{CO}\right.$, and $\left.{ }^{15} \mathrm{O}-\mathrm{O}_{2}\right)$, Muzik et al. found that oxygen extraction and metabolic rate were significantly higher in BAT-positive versus BAT-negative subjects, though BAT likely contributed less than $20 \mathrm{kcal} / \mathrm{d}$ to overall energy expenditure (53). Although that may seem like a small contribution, over time it could equate to significant caloric expenditures. Indeed, Yoneshiro et al. showed, using repeated cold exposure, negative correlations between changes in BAT activity and body fat mass (54).

\section{Perfusion}

Activation of BAT is associated with increases in tissue perfusion (34). One method for estimating the blood perfusion rate is by measuring oxygen consumption using ${ }^{15} \mathrm{O}-\mathrm{H}_{2} \mathrm{O}$ PET. Orava et al. found on cold exposure, glucose uptake in BAT increased by a factor of 12 and perfusion doubled (35). The increase in perfusion was also positively correlated with whole-body energy expenditure $(r=0.45, P=0.021)$. Another commonly used perfusion tracer, ${ }^{13} \mathrm{~N}$-ammonia, has also been shown to effectively image BAT blood flow (55). Madar et al. showed that mean ${ }^{13} \mathrm{~N}$-ammonia $\mathrm{SUV}_{\max }$ in the supraclavicular BAT of 9 subjects increased from close to 0 during a warm condition to 3.1 during cold exposure.

Several MR techniques have been used to evaluate BAT blood flow. Functional MRI studies, taking advantage of the T2-weighted blood oxygen level-dependent (BOLD) signal, have demonstrated feasibility in monitoring BAT perfusion changes associated with activation (56). During cold activation, Chen et al. calculated a mean BOLD signal increase of $10.7 \%$ in areas corresponding to active BAT on ${ }^{18} \mathrm{~F}$-FDG PET images. A challenge with the MRI studies is the sensitivity of the MRI signals to motion, which can degrade signal quality.

Contrast-enhanced ultrasound is a method relying on the differential reflective ability of soft tissues and administered contrast agents to produce images of sound wave propagation. Flynn et al. used this method to investigate blood perfusion in cold-activated BAT and found BAT-positive subjects exhibited higher perfusion rates in supraclavicular fat than BAT-negative subjects (57). They also noted, interestingly, that the 3 subjects with the lowest BAT ${ }^{18}$ F-FDG uptake also had low BAT blood flow during a warm condition and their BAT failed to exhibit an increase in blood flow during cold exposure.

\section{Lipid Metabolism}

Several studies have demonstrated increases in the CT radio density of BAT (Supplemental Fig. 4) associated with its activation $(52,58)$. This finding is consistent with use of intracellular lipid stores as fuel (at least initially) for thermogenesis, and as the fraction of fat in the BAT declines the HU rise closer to those of water. On the basis of the differing proton precessional frequencies in water versus fat, chemical shift water-fat MRI can be used to characterize tissue fat fraction. When this method is used in conjunction with a BAT activation procedure, the fat fraction of BAT has been shown to decrease with BAT activation, presumably due to metabolism of intracellular triglycerides or increased perfusion (59).

In rodents, a significant amount of circulating triglycerides have been shown to be extracted by BAT (32), though the contribution from NEFA uptake appears to be a relatively small fraction of total BAT metabolism during cold-induced thermogenesis compared with intracellular brown adipocyte triglycerides (60). Similarly, using ${ }^{18} \mathrm{~F}$-fluoro-thiaheptadecanoic acid (FTHA), a fatty acid tracer, Ouellet et al. found that in humans, whereas NEFA uptake in 
TABLE 3

Human Studies of Imaging Methods Used to Identify and Quantify BAT Activity

\begin{tabular}{|c|c|c|c|}
\hline Biologic target & Signal source & Modality & Reference \\
\hline Glucose metabolism & ${ }^{18} \mathrm{~F}-\mathrm{FDG}$ & PET & 11 \\
\hline Adrenergic innervation & ${ }^{123}$ I-MIBG & SPECT & 91 \\
\hline \multirow[t]{3}{*}{ Sympathetic innervation } & ${ }^{18} \mathrm{~F}$-DOPA & PET & 22 \\
\hline & ${ }^{11} \mathrm{C}-\mathrm{MRB}$ & PET & 63 \\
\hline & ${ }^{11} \mathrm{C}-\mathrm{HED}$ & PET & 64 \\
\hline Tissue density & X-ray & CT & 58 \\
\hline \multirow[t]{5}{*}{ Perfusion } & ${ }^{15} \mathrm{O}-\mathrm{H}_{2} \mathrm{O}$ & PET & 35 \\
\hline & ${ }^{13} \mathrm{~N}-\mathrm{NH}_{3}$ & PET & 55 \\
\hline & ${ }^{99 m} \mathrm{Tc}-\mathrm{MIBI}$ & SPECT & 21 \\
\hline & BOLD & MR & 56 \\
\hline & Sound reflection & CEUS & 57 \\
\hline \multirow[t]{3}{*}{ Temperature } & Infrared radiation & $\mathrm{IRT}$ & 92 \\
\hline & ${ }^{1} \mathrm{H}$ & MRS & 93 \\
\hline & Microwave radiation & Radiometry & 61 \\
\hline NEFA metabolism & ${ }^{18}$ F-FTHA & PET & 52 \\
\hline \multirow[t]{2}{*}{ Oxidative metabolism } & ${ }^{11} \mathrm{C}$-acetate & PET & 52 \\
\hline & ${ }^{15} \mathrm{O}$ & PET & 53 \\
\hline BAT lipid consumption & Water-fat & MR & 94 \\
\hline \multirow[t]{2}{*}{ TN BAT detection } & Dual echo & MR & 95 \\
\hline & DIXON & MR & 96 \\
\hline Somatostatin receptors & ${ }^{68} \mathrm{Ga}-\mathrm{DOTA}-\mathrm{NOC}$ & PET & 97 \\
\hline Oxygen consumption & ${ }^{15} \mathrm{O}-\mathrm{O}_{2}$ & PET & 36 \\
\hline TSPO density & ${ }^{11} \mathrm{C}-\mathrm{PBR} 28$ & PET & 68 \\
\hline CB1R density & ${ }^{18}$ F-FMPEP- $d_{2}$ & PET & 67 \\
\hline BAT composition & Ultrasonic Waves & MSOT & 98 \\
\hline
\end{tabular}

$\mathrm{TN}=$ thermoneutral.

BAT increased during cold exposure, circulating NEFAs likely contributed little to total BAT oxidative metabolism (52). These findings were supported by a subsequent study, also using ${ }^{18} \mathrm{~F}$ FTHA, that showed although NEFA uptake was strongly correlated with daily energy expenditure (during both warm and cold conditions), it likely contributed significantly less to whole-body energy expenditure than skeletal muscle (36). NEFA uptake in BAT was significantly increased during cold exposure, and the contribution of NEFA uptake toward BAT energy expenditure was negatively (though not significantly) correlated with the quantity of stored lipids within BAT (as assessed using CT Hounsfield units). These findings indicate that circulating fatty acids are either taken up and directly oxidized, or replenish endogenous BAT triglycerides stores that have been depleted to fuel BAT thermogenesis.

\section{OTHER BAT IMAGING TRACERS AND TECHNIQUES}

Novel techniques are also being investigated that may shed light on previously unexplored aspects of BAT function. We have reported on using microwave radiometry to estimate the temperature of BAT in vivo in humans (61). Although this technique is feasible and was able to show population differences, it was slow, did not generate images (except as count densities displayed on an anatomic format), and was not clearly suitable for use in individual patient measurements due to variance. Thermography has similar limitations, although possibly more promise (62). The challenges with thermography include its visualization of very superficial tissues, as opposed to deeper structures, which include BAT.

BAT sympathetic innervation has been targeted using several radiotracers. Although not yet used in a prospective human trial, Hadi et al. reviewed ${ }^{18} \mathrm{~F}$-DOPA images of patients with suspected pheochromocytomas and found incidental BAT uptake in $17.9 \%$ of patients (22). A highly selective norepinephrine transporter ligand, ${ }^{11} \mathrm{C}-(\mathrm{S}, \mathrm{S})-{ }^{11} \mathrm{C}-\mathrm{O}-\mathrm{methylreboxetine}$ (MRB), was found by Hwang et al. to show very similar levels of BAT uptake under both cold-activated and thermoneutral conditions (63). Muzik et al. investigated the relationship between sympathetic innervation and cold-activated levels of BAT using ${ }^{11} \mathrm{C}$-meta-hydroxyephedrin (HED; Fig. 4) and ${ }^{18}$ F-FDG (64). They showed that the retention index of ${ }^{11} \mathrm{C}-\mathrm{HED}$ is a useful predictor of levels of cold-activated BAT. 


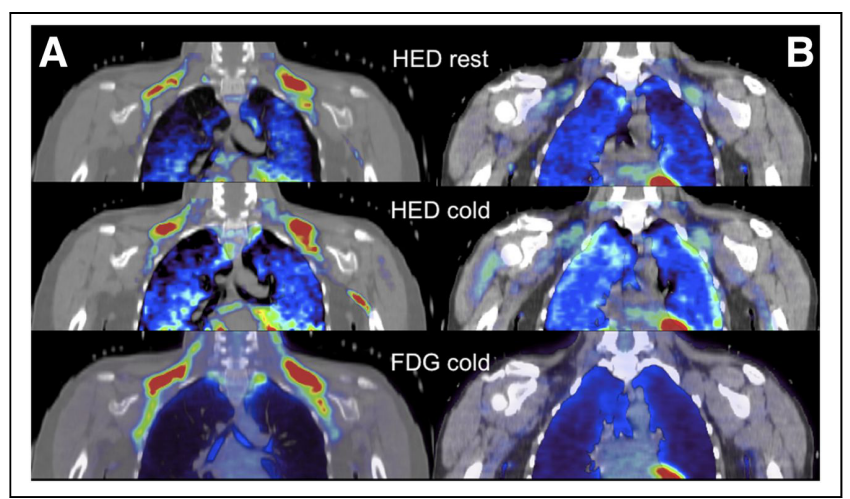

FIGURE 4. ${ }^{11} \mathrm{C}-\mathrm{HED}$ PET tracer uptake in supraclavicular BAT during thermoneutral condition $\left({ }^{11} \mathrm{C}-\mathrm{HED}\right.$ rest, upper row), during cold exposure $\left({ }^{11} \mathrm{C}-\mathrm{HED}\right.$ cold, middle row), and ${ }^{18} \mathrm{~F}-\mathrm{FDG}$ tracer uptake during cold exposure $\left({ }^{18} \mathrm{~F}\right.$-FDG cold, bottom row) in subject with cold-activated BAT (A) and subject without cold-activated BAT (B). (Reprinted from (64).)

As heat production in BAT is accomplished by circumventing the ATPase-facilitated proton transfer across the mitochondrial inner membrane, the most direct measure of BAT activity should be quantifying the mitochondrial membrane potential. The PET imaging agent ${ }^{18} \mathrm{~F}$-fluorobenzyltriphenyl phosphonium $\left({ }^{18} \mathrm{~F}\right.$-FBnTP; Fig. 5) is an indicator of mitochondrial membrane potential, which may be useful for measuring true BAT volume (i.e., activatable and "dormant" BAT) as well as BAT thermogenic activity (65).

The endocannabinoid system is involved in the control of glucose and lipid metabolism and activation of cannabinoid type 1 receptors (CB1R) and is known to inhibit energy expenditure and

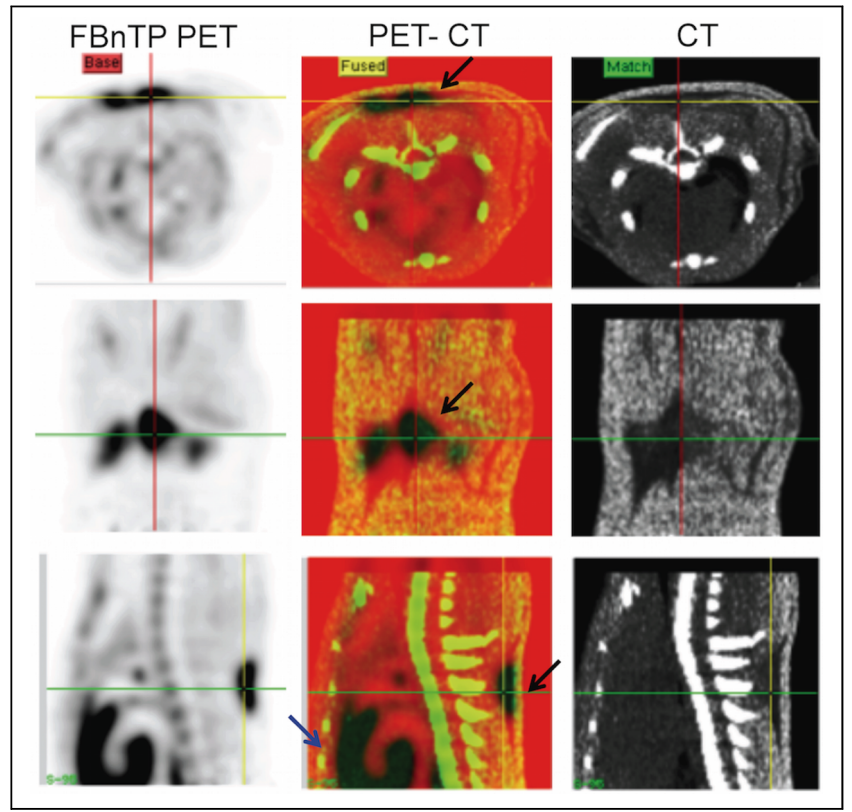

FIGURE 5. ${ }^{18} \mathrm{~F}$-FBnTP uptake in interscapular brown fat depots at room temperature. PET/CT images in transverse (upper panel), coronal (mid panel), and sagittal (lower panel) view, acquired in a rat at room temperature. Increased ${ }^{18} \mathrm{~F}$-FBnTP uptake in the interscapular area is confined to CT regions of low Hounsfield units (black arrows). Note the strong uptake of ${ }^{18} \mathrm{~F}-\mathrm{FBnTP}$ in BAT, similar to that seen in heart (blue arrow). (Reprinted with permission of (65).) thermogenesis. CB1R density in the brain has been quantified using a CB1R antagonist radioligand, (3R,5R)-5-(3- $\left({ }^{18} \mathrm{~F}\right.$-fluoromethoxy)phenyl)-3(((R)-1-phenylethyl)amino)-1-(4-(trifluoromethyl)phenyl)pyrrolidin-2-one $\left({ }^{18} \mathrm{~F}-\mathrm{FMPEP}-d_{2}\right)$. Eriksson et al. showed in vivo binding of ${ }^{18} \mathrm{~F}$-FMPEP- $d_{2}$ to BAT in rodents (66). Subsequently, Lahesmaa et al. showed elevated ${ }^{18} \mathrm{~F}-\mathrm{FMPEP}-d_{2}$ BAT uptake (Fig. 6), indicating increased CB1R density, in lean men after cold activation, whereas overweight men exhibited decreased ${ }^{18} \mathrm{~F}$ FMPEP- $d_{2}$ BAT uptake (67).

Because of an abundance of translocator proteins (TSPO) on the outer membrane of mitochondria, ${ }^{11} \mathrm{C}$-peripheral benzodiazepine receptor-28 ( $\left({ }^{11} \mathrm{C}-\mathrm{PBR} 28\right)$ has been shown potentially useful for imaging BAT in thermoneutral conditions (68). This PET tracer can be challenging to work with; however, given its sensitivity to genotype. A recent study shows ${ }^{11} \mathrm{C}$-labeled biotin accumulates significantly in BAT (69). Biotin is taken up by cells via the sodium-dependent multivitamin transporter, a transmembrane protein highly expressed in the gastrointestinal tract, liver, kidneys, heart, and also cancer cells. Biotindependent enzymes are used for lipolysis, glucose metabolism, and fatty-acid synthesis, which may explain the strong BAT uptake of biotin in rodents described by Bongarzone et al. (69). As BAT is known to take up glucose and fatty acids under thermoneutral conditions, ${ }^{11} \mathrm{C}$-biotin may be useful for imaging unstimulated BAT.

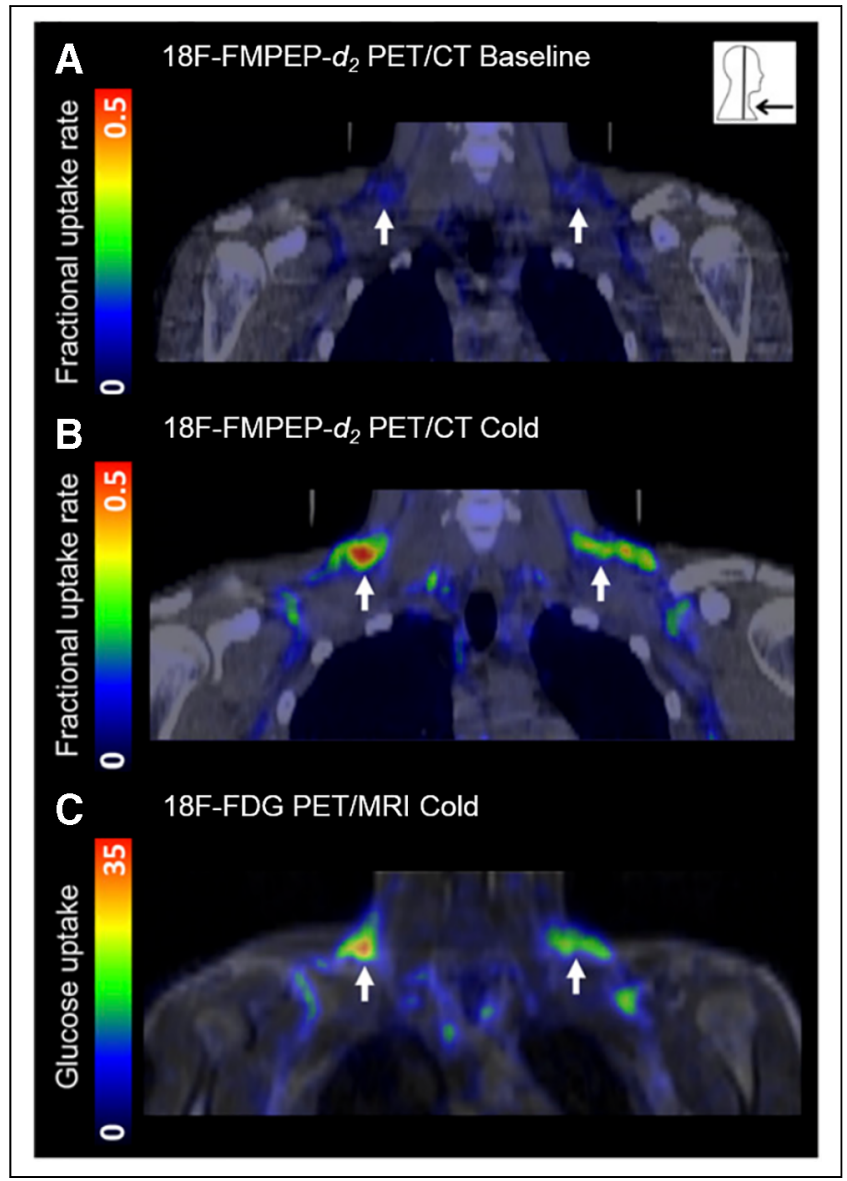

FIGURE 6. Imaging with ${ }^{18} \mathrm{~F}-\mathrm{FMPEP}-\mathrm{d}_{2} \mathrm{PET} / \mathrm{CT}$ in a thermoneutral (A) and cold (B) conditions and with ${ }^{18} \mathrm{~F}-\mathrm{FDG}$ PET/MRI in a cold condition (C). Coronal PET images from 1 lean study subject with arrows indicating supraclavicular BAT. (Reprinted with permission of (67).) 


\section{INTERVENTIONAL APPROACHES}

Obesity rates in the United States and around the world continue to rise, posing significant risks to public health. BAT represents a promising potential target for the treatment of obesity and related metabolic disorders. Exposure to cold is the most potent activator of BAT and has thus been increasingly assessed as a therapy $(54,70)$. Exercise and pharmacologic approaches have also been evaluated $(70,71)$. A search of ClinicalTrials.gov found 14 active projects currently listed (Supplemental Table 1; supplemental materials are available at http://jnm.snmjournals.org), which aim to evaluate interventions intended to increase BAT activity or mass. Most of these studies (11/14), as well as those already completed, use ${ }^{18} \mathrm{~F}$ FDG PET to monitor changes in BAT. To effectively assess changes in BAT using this method, an understanding of the test-retest repeatability of ${ }^{18} \mathrm{~F}$-FDG PET/CT in the assessment of active BAT is necessary. We studied the repeatability of ${ }^{18} \mathrm{~F}-\mathrm{FDG}$ uptake in BAT using 2 different cold-activation approaches. Eleven volunteers were cooled by placing their feet on a block of ice intermittently while sitting in a cooled room followed by an ${ }^{18} \mathrm{~F}-\mathrm{FDG}$ PET/CT scan (72). This procedure was then repeated within $14 \mathrm{~d}$. BAT metabolic volume and $\mathrm{SUV}_{\text {max }}$ were found to be significantly correlated between imaging sessions. In a separate study using an individualized cooling protocol involving a full-body water perfusion suit, BAT ${ }^{18} \mathrm{~F}-\mathrm{FDG}$ uptake metrics extracted from both PET/CT and PET/MR images (Supplemental Fig. 5) showed strong repeatability (73). Though ${ }^{18}$ F-FDG PET imaging of BAT appears less repeatable compared with ${ }^{18} \mathrm{~F}$ FDG PET imaging of tumors, these studies show it is a useful modality with the clear potential for monitoring BAT response to interventions.

\section{CONCLUSION}

Molecular imaging with ${ }^{18}$ F-FDG PET/CT unexpectedly established BAT to be present and active/activatable in many adults in addition to its expected presence in children. In the clinical practice of nuclear medicine, suppressing BAT activity on ${ }^{18}$ F-FDG PET with appropriate patient preparation is important to avoid false-positive or false-negative PET scans, particularly in very young patients. BAT biology is complex, but preclinical studies have shown that chronic activation of BAT can have favorable effects on glucose and lipid metabolic status and that transplantation of BAT in preclinical models can ameliorate diabetes. Not all of these effects are due to consumption of glucose or lipids by the BAT but appear related to endocrine activity of BAT, effects which are still being defined. Anatomic and molecular imaging tools of a variety of types have been used to assess the presence, activity, and quantity of BAT and to help dissect its complex metabolism. These tools are essential to advancing research in this area, research focused on increasing BAT activity. Although imaging approaches using nonionizing radiation are of great interest, especially for longitudinal studies, ${ }^{18} \mathrm{~F}$-FDG PET/CT currently remains the gold standard method for assessment of the presence, activity and volume of active BAT (33).

\section{KEY POINTS}

QUESTION: How has molecular imaging influenced our understanding of human BAT?

PERTINENT FINDINGS: Molecular imaging with ${ }^{18} \mathrm{~F}-\mathrm{FDG}$ and other radiotracers has established that BAT is present, often active or activatable, and its presence is related to metabolic health.
IMPLICATIONS FOR PATIENT CARE: Identification of BAT as a previously unrecognized endocrine-like tissue opens therapeutic opportunities for weight loss and improvement of glucose and lipid profiles.

\section{DISCLOSURE}

No potential conflict of interest relevant to this article was reported.

\section{REFERENCES}

1. Gessner C. Conradi Gesneri medici Tigurini Historice animalium Lib. I. de quadrupedibus uiuiparis: opus philosophis, medicis, grammaticis, philologis, poëtis, \& omnibus rerum linguarumq́; uariarum studiosis, utilissimum simul iucundissimumq́; futurum. Vol Liber 1 (1551); Liber 2 (1586). Tiguri: Apud Christ. Froschouerum; 1551.

2. Afzelius BA. Brown adipose tissue: its gross anatomy, histology and cytology. In: Brown Adipose Tissue. Elsevier: 1970:1-28.

3. Lean ME. Brown adipose tissue in humans. Proc Nutr Soc. 1989;48:243-256.

4. Scheja L, Heeren J. The endocrine function of adipose tissues in health and cardiometabolic disease. Nat Rev Endocrinol. 2019;15:507-524.

5. Kortelainen ML, Pelletier G, Ricquier D, Bukowiecki LJ. Immunohistochemical detection of human brown adipose tissue uncoupling protein in an autopsy series. $J$ Histochem Cytochem. 1993;41:759-764.

6. Sisson JC, Lynch JJ, Johnson J, et al. Scintigraphic detection of regional disruption of adrenergic neurons in the heart. Am Heart J. 1988;116:67-76.

7. Nakajo M, Shapiro B, Copp J, et al. The normal and abnormal distribution of the adrenomedullary imaging agent $\mathrm{m}$-[I-131]iodobenzylguanidine (I-131 MIBG) in man: evaluation by scintigraphy. J Nucl Med. 1983;24:672-682.

8. Barrington SF, Maisey MN. Skeletal muscle uptake of fluorine-18-FDG: effect of oral diazepam. J Nucl Med. 1996;37:1127-1129.

9. Engel H, Steinert H, Buck A, Berthold T, Huch Böni RA, von Schulthess GK. Whole-body PET: physiological and artifactual fluorodeoxyglucose accumulations. J Nucl Med. 1996;37:441-446.

10. Wahl RL, Barrington SF, Maisey MM. Atlas of Clinical Positron Emission Tomography. CRC Press; 1999.

11. Hany TF, Gharehpapagh E, Kamel EM, Buck A, Himms-Hagen J, von Schulthess GK. Brown adipose tissue: a factor to consider in symmetrical tracer uptake in the neck and upper chest region. Eur J Nucl Med Mol Imaging. 2002;29:1393-1398.

12. Cohade C, Mourtzikos KA, Wahl RL. "USA-Fat": prevalence is related to ambient outdoor temperature-evaluation with ${ }^{18} \mathrm{~F}-\mathrm{FDG} \quad \mathrm{PET} / \mathrm{CT} . \quad \mathrm{J}$ Nucl $\mathrm{Med}$. 2003;44:1267-1270.

13. Cohade C, Osman M, Pannu HK, Wahl RL. Uptake in supraclavicular area fat ("USA-Fat"): description on ${ }^{18}$ F-FDG PET/CT. J Nucl Med. 2003;44:170-176.

14. Minotti AJ, Shah L, Keller K. Positron emission tomography/computed tomography fusion imaging in brown adipose tissue. Clin Nucl Med. 2004;29:5-11.

15. Tatsumi M, Engles JM, Ishimori T, Nicely O, Cohade C, Wahl RL. Intense ${ }^{18} \mathrm{~F}$ FDG uptake in brown fat can be reduced pharmacologically. J Nucl Med. 2004;45:1189-1193.

16. Laurberg JM, Olsen AK, Hansen SB, et al. Imaging of vulnerable atherosclerotic plaques with FDG-microPET: no FDG accumulation. Atherosclerosis. 2007;192:275-282.

17. Fukuchi K, Tatsumi M, Ishida Y, Oku N, Hatazawa J, Wahl RL. Radionuclide imaging metabolic activity of brown adipose tissue in a patient with pheochromocytoma. Exp Clin Endocrinol Diabetes. 2004;112:601-603.

18. Kyparos D, Arsos G, Georga S, et al. Assessment of brown adipose tissue activity in rats by ${ }^{99 \mathrm{~m}} \mathrm{Tc}$-sestamibi uptake. Physiol Res. 2006;55:653-659.

19. Baba S, Engles JM, Huso DL, Ishimori T, Wahl RL. Comparison of uptake of multiple clinical radiotracers into brown adipose tissue under cold-stimulated and nonstimulated conditions. J Nucl Med. 2007;48:1715-1723.

20. Paul R, Kiuru A, Söderström KO, et al. Organ and tumor distribution of $\left({ }^{18} \mathrm{~F}\right)$-2-fluoro-2-deoxy-D-glucose in fasting and non-fasting rats. Life Sci. 1987;40:1609-1616.

21. Goetze S, Lavely WC, Ziessman HA, Wahl RL. Visualization of brown adipose tissue with ${ }^{99 \mathrm{~m}} \mathrm{Tc}$-methoxyisobutylisonitrile on SPECT/CT. J Nucl Med. 2008;49:752-756.

22. Hadi M, Chen CC, Whatley M, Pacak K, Carrasquillo JA. Brown fat imaging with ${ }^{18}$ F-6-fluorodopamine PET/CT, ${ }^{18}$ F-FDG PET/CT, and ${ }^{123} \mathrm{I}$-MIBG SPECT: a study of patients being evaluated for pheochromocytoma. J Nucl Med. 2007;48:1077-1083.

23. Saito M, Okamatsu-Ogura Y, Matsushita M, et al. High incidence of metabolically active brown adipose tissue in healthy adult humans: effects of cold exposure and adiposity. Diabetes. 2009;58:1526-1531. 
24. Cypess AM, Lehman S, Williams G, et al. Identification and importance of brown adipose tissue in adult humans. $N$ Engl J Med. 2009;360:1509-1517.

25. van Marken Lichtenbelt WD, Vanhommerig JW, Smulders NM, et al. Cold-activated brown adipose tissue in healthy men. $N$ Engl J Med. 2009;360:1500-1508.

26. Virtanen KA, Lidell ME, Orava J, et al. Functional brown adipose tissue in healthy adults. $N$ Engl J Med. 2009;360:1518-1525.

27. Lee P, Greenfield JR, Ho KK, Fulham MJ. A critical appraisal of the prevalence and metabolic significance of brown adipose tissue in adult humans. Am J Physiol Endocrinol Metab. 2010;299:E601-E606.

28. McDonald RB, Murtagh CM, Horwitz BA. Age and gender effects on glucose utilization in skeletal muscle and brown adipose tissue of cold-exposed rats. Proc Soc Exp Biol Med. 1994;207:102-109.

29. Yoneshiro T, Aita S, Matsushita M, et al. Age-related decrease in cold-activated brown adipose tissue and accumulation of body fat in healthy humans. Obesity (Silver Spring). 2011;19:1755-1760.

30. Matsushita M, Yoneshiro T, Aita S, Kameya T, Sugie H, Saito M. Impact of brown adipose tissue on body fatness and glucose metabolism in healthy humans. Int $J$ Obes (Lond). 2014;38:812-817.

31. Chen KY, Cypess AM, Laughlin MR, et al. Brown Adipose Reporting Criteria in Imaging STudies (BARCIST 1.0): recommendations for standardized FDG-PET/ CT experiments in humans. Cell Metab. 2016;24:210-222.

32. Bartelt A, Bruns OT, Reimer R, et al. Brown adipose tissue activity controls triglyceride clearance. Nat Med. 2011;17:200-205.

33. Zhang F, Hao G, Shao M, et al. An adipose tissue atlas: an image-guided identification of human-like BAT and beige depots in rodents. Cell Metab. 2018;27:252-262.e3.

34. Foster DO, Frydman ML. Tissue distribution of cold-induced thermogenesis in conscious warm- or cold-acclimated rats reevaluated from changes in tissue blood flow: the dominant role of brown adipose tissue in the replacement of shivering by nonshivering thermogenesis. Can J Physiol Pharmacol. 1979;57:257-270.

35. Orava J, Nuutila P, Lidell ME, et al. Different metabolic responses of human brown adipose tissue to activation by cold and insulin. Cell Metab. 2011;14:272-279.

36. U Din M, Raiko J, Saari T, et al. Human brown adipose tissue $\left[{ }^{15} \mathrm{O}\right] \mathrm{O} 2 \mathrm{PET}$ imaging in the presence and absence of cold stimulus. Eur J Nucl Med Mol Imaging. 2016;43:1878-1886.

37. Arch JR. Challenges in $\beta(3)$-adrenoceptor agonist drug development. Ther Adv Endocrinol Metab. 2011;2:59-64.

38. Blondin DP, Nielsen S, Kuipers EN, et al. Human brown adipocyte thermogenesis is driven by $\beta 2-A R$ stimulation. Cell Metab. 2020;32:287-300.e7.

39. Severinsen MCK, Schéele C, Pedersen BK. Exercise and browning of white adipose tissue - a translational perspective. Curr Opin Pharmacol. 2020;52:18-24.

40. Chondronikola M, Beeman SC, Wahl RL. Non-invasive methods for the assessment of brown adipose tissue in humans. J Physiol (Lond). 2018;596:363-378.

41. Cannon B, Nedergaard J. Brown adipose tissue: function and physiological significance. Physiol Rev. 2004;84:277-359.

42. Sanchez-Delgado G, Martinez-Tellez B, Garcia-Rivero Y, et al. Brown adipose tissue and skeletal muscle ${ }^{18} \mathrm{~F}$-FDG activity after a personalized cold exposure is not associated with cold-induced thermogenesis and nutrient oxidation rates in young healthy adults. Front Physiol. 2018;16:1577.

43. White JD, Dewal RS, Stanford KI. The beneficial effects of brown adipose tissue transplantation. Mol Aspects Med. 2019.

44. Lee MW, Lee M, Oh KJ. adipose tissue-derived signatures for obesity and type 2 diabetes: adipokines, batokines and microRNAs. J Clin Med. 2019;8:854.

45. Hondares E, Iglesias R, Giralt A, et al. Thermogenic activation induces FGF21 expression and release in brown adipose tissue. $J$ Biol Chem. 2011;286:12983-12990.

46. Lee P, Brychta RJ, Linderman J, Smith S, Chen KY, Celi FS. Mild cold exposure modulates fibroblast growth factor 21 (FGF21) diurnal rhythm in humans: relationship between FGF21 levels, lipolysis, and cold-induced thermogenesis. J Clin Endocrinol Metab. 2013;98:E98-E102.

47. Villarroya J, Cereijo R, Gavalda-Navarro A, Peyrou M, Giralt M, Villarroya F. New insights into the secretory functions of brown adipose tissue. $J$ Endocrinol. 2019;243:R19-R27.

48. Ouellet V, Routhier-Labadie A, Bellemare W, et al. Outdoor temperature, age, sex, body mass index, and diabetic status determine the prevalence, mass, and glucoseuptake activity of ${ }^{18}$ F-FDG-detected BAT in humans. J Clin Endocrinol Metab. 2011;96:192-199.

49. Au-Yong IT, Thorn N, Ganatra R, Perkins AC, Symonds ME. Brown adipose tissue and seasonal variation in humans. Diabetes. 2009;58:2583-2587.

50. Steinberg JD, Vogel W, Vegt E. Factors influencing brown fat activation in FDG PET/CT: a retrospective analysis of $15,000+$ cases. $\mathrm{Br} J$ Radiol. 2017;90:20170093.
51. Orava J, Nuutila P, Noponen T, et al. Blunted metabolic responses to cold and insulin stimulation in brown adipose tissue of obese humans. Obesity (Silver Spring). 2013;21:2279-2287.

52. Ouellet V, Labbe SM, Blondin DP, et al. Brown adipose tissue oxidative metabolism contributes to energy expenditure during acute cold exposure in humans. $J$ Clin Invest. 2012;122:545-552.

53. Muzik O, Mangner TJ, Granneman JG. Assessment of oxidative metabolism in brown fat using PET imaging. Front Endocrinol (Lausanne). 2012;3:15.

54. Yoneshiro T, Aita S, Matsushita M, et al. Recruited brown adipose tissue as an antiobesity agent in humans. J Clin Invest. 2013;123:3404-3408.

55. Madar I, Wahl R, Crandall J, Dannals R. ${ }^{13} \mathrm{~N}$-ammonia: A novel biomarker for blood flow-dependent imaging of brown adipose tissue in rodents and humans. $J$ Nucl Med. 2016;57(suppl. 2):1696.

56. Chen YC, Cypess AM, Palmer M, Kolodny G, Kahn CR, Kwong KK. Measurement of human brown adipose tissue volume and activity using anatomic MR imaging and functional MR imaging. J Nucl Med. 2013;54:1584-1587.

57. Flynn A, Li Q, Panagia M, et al. Contrast-enhanced ultrasound: a novel noninvasive, nonionizing method for the detection of brown adipose tissue in humans. $J$ Am Soc Echocardiogr. 2015;28:1247-1254.

58. Baba S, Jacene HA, Engles JM, Honda H, Wahl RL. CT Hounsfield units of brown adipose tissue increase with activation: preclinical and clinical studies. J Nucl Med. 2010;51:246-250.

59. Gifford A, Towse TF, Walker RC, Avison MJ, Welch EB. Characterizing active and inactive brown adipose tissue in adult humans using PET-CT and MR imaging. Am J Physiol Endocrinol Metab. 2016;311:E95-E104.

60. Ma SW, Foster DO. Uptake of glucose and release of fatty acids and glycerol by rat brown adipose tissue in vivo. Can J Physiol Pharmacol. 1986;64:609-614

61. Crandall J, Gajwani P, Mawhinney D, Sterzer F, Wahl R. Passive microwave radiometry for the non-invasive detection of human brown fat: First human studies with direct correlation to FDG/PET. J Nucl Med. 2014;55(suppl. 1):1648.

62. Lee P, Ho KK, Greenfield JR. Hot fat in a cool man: infrared thermography and brown adipose tissue. Diabetes Obes Metab. 2011;13:92-93.

63. Hwang JJ, Yeckel CW, Gallezot JD, et al. Imaging human brown adipose tissue under room temperature conditions with ${ }^{11} \mathrm{C}-\mathrm{MRB}$, a selective norepinephrine transporter PET ligand. Metabolism. 2015;64:747-755.

64. Muzik O, Mangner TJ, Leonard WR, Kumar A, Granneman JG. Sympathetic innervation of cold-activated brown and white fat in lean young adults. J Nucl Med. 2017;58:799-806.

65. Madar I, Naor E, Holt D, Ravert H, Dannals R, Wahl R. Brown adipose tissue response dynamics: in vivo insights with the voltage sensor ${ }^{18} \mathrm{~F}$-fluorobenzyl triphenyl phosphonium. PLoS One. 2015;10:e0129627.

66. Eriksson O, Mikkola K, Espes D, et al. The cannabinoid receptor-1 is an imaging biomarker of brown adipose tissue. J Nucl Med. 2015;56:1937-1941.

67. Lahesmaa M, Eriksson O, Gnad T, et al. Cannabinoid type 1 receptors are upregulated during acute activation of brown adipose tissue. Diabetes. 2018;67:1226-1236.

68. Ran C, Albrecht DS, Bredella MA, et al. PET imaging of human brown adipose tissue with the TSPO tracer $\left[{ }^{11} \mathrm{C}\right] \mathrm{PBR} 28$. Mol Imaging Biol. 2018;20:188-193.

69. Bongarzone S, Sementa T, Dunn J, et al. Imaging biotin trafficking in vivo with positron emission tomography. J Med Chem. 2020;63:8265-8275.

70. Peres Valgas da Silva C, Hernandez-Saavedra D, White JD, Stanford KI. Cold and exercise: therapeutic tools to activate brown adipose tissue and combat obesity. Biology (Basel). 2019;8:9.

71. O'Mara AE, Johnson JW, Linderman JD, et al. Chronic mirabegron treatment increases human brown fat, HDL cholesterol, and insulin sensitivity. J Clin Invest. 2020;130:2209-2219.

72. Crandall JP, Gajwani P. O JH, Mawhinney DD, Sterzer F, Wahl RL. Repeatability of brown adipose tissue measurements on FDG PET/CT following a simple cooling procedure for BAT activation. PLoS One. 2019;14:e0214765.

73. Fraum TJ, Crandall JP, Ludwig DR, et al. Repeatability of quantitative brown adipose tissue imaging metrics on positron emission tomography with ${ }^{18} \mathrm{~F}$-fluorodeoxyglucose in humans. Cell Metab. 2019;30:212-224.e4.

74. Lin SF, Fan X, Yeckel CW, et al. Ex vivo and in vivo evaluation of the norepinephrine transporter ligand $\left[{ }^{11} \mathrm{C}\right] \mathrm{MRB}$ for brown adipose tissue imaging. $\mathrm{Nucl}$ Med Biol. 2012;39:1081-1086.

75. Min JJ, Biswal S, Deroose C, Gambhir SS. Tetraphenylphosphonium as a novel molecular probe for imaging tumors. J Nucl Med. 2004;45:636-643.

76. Azhdarinia A, Daquinag AC, Tseng C, et al. A peptide probe for targeted brown adipose tissue imaging. Nat Commun. 2013;4:2472.

77. Crane JD, Mottillo EP, Farncombe TH, Morrison KM, Steinberg GR. A standardized infrared imaging technique that specifically detects UCP1-mediated thermogenesis in vivo. Mol Metab. 2014;3:490-494. 
78. Antonacci MA, McHugh C, Kelley M, McCallister A, Degan S, Branca RT. Direct detection of brown adipose tissue thermogenesis in UCP1-/- mice by hyperpolarized ${ }^{129}$ Xe MR thermometry. Sci Rep. 2019;9:14865.

79. Zhang X, Kuo C, Moore A, Ran C. In vivo optical imaging of interscapular brown adipose tissue with ${ }^{18}$ F-FDG via Cerenkov luminescence imaging. PLoS One. 2013;8:e62007.

80. Lau AZ, Chen AP, Gu Y, Ladouceur-Wodzak M, Nayak KS, Cunningham CH. Noninvasive identification and assessment of functional brown adipose tissue in rodents using hyperpolarized ${ }^{13} \mathrm{C}$ imaging. Int J Obes (Lond). 2014;38:126-131.

81. Panagia M, Yang J, Gale E, et al. A novel tracer for in vivo optical imaging of fatty acid metabolism in the heart and brown adipose tissue. Sci Rep. 2020;10:11209.

82. Strobel K, van den Hoff J, Pietzsch J. Localized proton magnetic resonance spectroscopy of lipids in adipose tissue at high spatial resolution in mice in vivo. J Lipid Res. 2008;49:473-480.

83. Nakayama A, Bianco AC, Zhang CY, Lowell BB, Frangioni JV. Quantitation of brown adipose tissue perfusion in transgenic mice using near-infrared fluorescence imaging. Mol Imaging. 2003;2:37-49.

84. Khanna A, Branca RT. Detecting brown adipose tissue activity with BOLD MRI in mice. Magn Reson Med. 2012;68:1285-1290.

85. Chen YI, Cypess AM, Sass CA, et al. Anatomical and functional assessment of brown adipose tissue by magnetic resonance imaging. Obesity (Silver Spring). 2012;20:1519-1526.

86. Hettich M, Braun F, Bartholomä MD, Schirmbeck R, Niedermann G. High-resolution PET imaging with therapeutic antibody-based PD-1/PD-L1 checkpoint tracers. Theranostics. 2016;6:1629-1640.

87. Hartimath SV, Khanapur S, Boominathan R, et al. Imaging adipose tissue browning using the TSPO-18kDa tracer $\left[{ }^{18}\right.$ F]FEPPA. Mol Metab. 2019;25:154-158.

88. Yang J, Yang J, Wang L, Moore A, Liang SH, Ran C. Synthesis-free PET imaging of brown adipose tissue and TSPO via combination of disulfiram and $64 \mathrm{CuCl} 2$. Sci Rep. 2017;7:8298.

89. Wang H, Wang M, Chansaenpak K, et al. A novel PET probe for brown adipose tissue imaging in rodents. Mol Imaging Biol. 2020;22:675-684.

90. Zhang X, Tian Y, Zhang H, et al. Curcumin analogues as selective fluorescence imaging probes for brown adipose tissue and monitoring browning. Sci Rep. 2015;5:13116.

91. Okuyama C, Ushijima Y, Kubota T, et al. ${ }^{123}$ I-Metaiodobenzylguanidine uptake in the nape of the neck of children: likely visualization of brown adipose tissue. $J$ Nucl Med. 2003;44:1421-1425.
92. Symonds ME, Henderson K, Elvidge L, et al. Thermal imaging to assess agerelated changes of skin temperature within the supraclavicular region co-locating with brown adipose tissue in healthy children. J Pediatr. 2012;161:892-898.

93. Koskensalo K, Raiko J, Saari T, et al. Human brown adipose tissue temperature and fat fraction are related to its metabolic activity. $J$ Clin Endocrinol Metab. 2017;102:1200-1207.

94. Hu HH, Perkins TG, Chia JM, Gilsanz V. Characterization of human brown adipose tissue by chemical-shift water-fat MRI. AJR. 2013;200:177-183.

95. Holstila M, Virtanen KA, Grönroos TJ, et al. Measurement of brown adipose tissue mass using a novel dual-echo magnetic resonance imaging approach: a validation study. Metabolism. 2013;62:1189-1198.

96. Holstila M, Pesola M, Saari T, et al. MR signal-fat-fraction analysis and T2* weighted imaging measure BAT reliably on humans without cold exposure. Metabolism. 2017;70:23-30.

97. Kagna O, Pirmisashvili N, Tshori S, Freedman N, Israel O, Krausz Y. Neuroendocrine tumor imaging with ${ }^{68} \mathrm{Ga}$-DOTA-NOC: physiologic and benign variants. AJR. 2014;203:1317-1323.

98. Reber J, Willershäuser M, Karlas A, et al. Non-invasive measurement of brown fat metabolism based on optoacoustic imaging of hemoglobin gradients. Cell Metab. 2018;27:689-701.e4.

99. Yeung HW, Grewal RK, Gonen M, Schoder H, Larson SM. Patterns of ${ }^{18}$ F-FDG uptake in adipose tissue and muscle: a potential source of false-positives for PET. $J$ Nucl Med. 2003;44:1789-1796.

100. Kim S, Krynyckyi BR, Machac J, Kim CK. Temporal relation between temperature change and FDG uptake in brown adipose tissue. Eur J Nucl Med Mol Imaging. 2008;35:984-989.

101. Jacene HA, Cohade CC, Zhang Z, Wahl RL. The relationship between patients' serum glucose levels and metabolically active brown adipose tissue detected by PET/ CT. Mol Imaging Biol. 2011;13:1278-1283.

102. Perkins AC, Mshelia DS, Symonds ME, Sathekge M. Prevalence and pattern of brown adipose tissue distribution of ${ }^{18} \mathrm{~F}-\mathrm{FDG}$ in patients undergoing PET-CT in a subtropical climatic zone. Nucl Med Commun. 2013;34:168-174.

103. Persichetti A, Sciuto R, Rea S, et al. Prevalence, mass, and glucose-uptake activity of ${ }^{18} \mathrm{~F}$-FDG-detected brown adipose tissue in humans living in a temperate zone of Italy. PLoS One. 2013;8:e63391.

104. Brendle C, Werner MK, Schmadl M, et al. Correlation of brown adipose tissue with other body fat compartments and patient characteristics: a retrospective analysis in a large patient cohort using PET/CT. Acad Radiol. 2018;25:102-110. 